\title{
Terminal transferase positive cells in testicular biopsy specimens from boys with acute lymphoblastic leukaemia
}

\author{
J M CHESSELLS, ${ }^{*}$ J R PINCOTT,* W DANIELS-LAKE*† \\ From the *Departments of Haematology and Histopathology, The Hospital for Sick Children, London, and \\ the †Department of Immunology, Royal Free Hospital School of Medicine, London
}

SUMMARY Thirty nine testicular biopsy samples from 37 boys with acute lymphoblastic leukaemia were examined histologically and analysed for the presence of terminal deoxynucleotidyl transferase (TdT) positive cells. Immunological and histological findings correlated in 35 samples. Thirty boys with histologically and immunologically negative biopsy specimens stopped treatment, two subsequently relapsed in the testis, and five relapsed in the marrow.

This examination of samples for TdT positive cells did not improve the precision of early diagnosis of testicular relapse.

Boys with acute lymphoblastic leukaemia (ALL) who have an isolated testicular relapse after electively stopping treatment and who receive further adequate treatment have a relatively better chance of prolonged remission than those relapsing at other sites. ${ }^{1}$ The routine analysis of the cellular composition of testicular biopsy specimens, particularly if taken at the time of stopping treatment, may facilitate early diagnosis of residual disease and further improve the therapeutic results. Unfortunately, however, in a recent series of 170 biopsies 13 patients $(7 \%)$, whose biopsy specimens were reported as histologically negative, subsequently relapsed in the testis, and a further 17 samples $(10 \%)$ were difficult to evaluate due to presence of inflammation and "crush" artefacts. ${ }^{2}$ It would therefore be important to improve the precision of assessment of minimal residual disease in the testis.

In most cases of childhood ALL $(>97 \%)$ the nuclear enzyme terminal deoxynucleotidyl transferase (TdT) can be found in most blast cells. ${ }^{34}$ In healthy subjects TdT positive cells are confined to the thymus $(50-80 \%)$, bone marrow $(0 \cdot 5-6 \%)$, and to occasional circulating lymphoid like cells $(<0 \cdot 2 \%) .{ }^{45}$ When immunologically specific anti-TdT reagents are used no TdT positive cells are detectable in peripheral lymphoid organs, such as lymph nodes, spleen, and tonsil and among lymphocytes of inflammatory infiltrates. The non-lymphoid parenchyma is also TdT negative. ${ }^{6}$

In this study TdT positive cellular infiltrates were investigated in the testicular biopsy specimens taken in one hospital over three years to determine the corAccepted for publication 27 May 1986 relation between histology and immunohistology and whether the presence of TdT positive cells in a histologically normal biopsy specimen was indicative of subsequent testicular relapse.

PATIENTS

Wedge biopsies of the testis were obtained from $37:$ boys with ALL. Repeat biopsies were obtained from two boys, and a total of 39 specimens were available for investigation. At biopsy 34 boys had clinically normal testes and three had overt clinical infiltration. Of the two boys who underwent a second biopsy, one had a previously negative biopsy and subsequently developed overt testicular infiltration. In the second boy swelling persisted despite the course of testicular irradiation.

The patients were treated as previously described. ${ }^{1}$ Patients with negative biopsy specimens received no further treatment, and boys with testicular infiltration were given local irradiation and further systemic and intrathecal chemotherapy.

These decisions were based on the routine histology reports made at the time of biopsy. The results of TdT analysis were evaluated in a blind study without knowledge of the histology except in one instance (see below). The biopsy specimens were subsequently reviewed histologically by one of us (JRP) without knowledge of clinical details and the results correlated with the immunological analysis and outcome of the patients. At the time of writing patients had been followed up for a minimum of 35 and a maximum of 65 months since the time of biopsy. 


\section{Material and methods}

\section{ROUTINE HISTOLOGY}

The testicular tissue, which had been formalin fixed, was embedded in paraffin wax; sections were cut at $5 \mu \mathrm{m}$ thickness and stained with haematoxylin and eosin. The sections were examined for evidence of maturation or any abnormality of the seminiferous tubules, interstitial tissue, and tunica albuginea. In particular, evidence was sought of any leukaemic or lymphocytic infiltrate in the interstitial tissue or tunica. The presence, nature, and severity of any infiltrate was noted.

\section{IMMUNOHISTOLOGY}

The samples for immunohistology were processed, as described by Thomas et al. ${ }^{6}$ Briefly, unfixed samples of testis and thymus (positive control) were placed on a slice of cork, covered with OCT (Raymond Lamb), and snap frozen in isopentane which had been cooled in liquid nitrogen. Sections $(6 \mu \mathrm{m})$ were mounted on glass slides and fixed for 15 minutes within a cryostat in cool $\left(0-4^{\circ} \mathrm{C}\right) 10 \%$ buffered formalin. Then sections were washed in phosphate buffered saline for 30 minutes at $20^{\circ} \mathrm{C}$.

Two methods of labelling were used. Rabbit antiTdT was applied using the indirect immunoperoxidase technique. Endogenous peroxidase was blocked using $0.3 \% \mathrm{H}_{2} \mathrm{O}_{2}$ in phosphate buffered saline $(\mathrm{pH} 7 \cdot 6,30 \% \mathrm{w} / \mathrm{v})$ for 30 minutes and washed in phosphate buffered saline for a further 10 minutes. Sections were stained using a rabbit anti-TdT first layer (Supertech, Bethesda, Minnesota, USA) at $4^{\circ} \mathrm{C}$ overnight followed by swine antirabbit-Ig-peroxidase (Dakopatt) at room temperature for $\mathbf{3 0}$ minutes. The reaction was developed using diaminobenzidine by conventional technique. ${ }^{6}$ Rabbit anti-TdT was also used in indirect immunofluorescence using goat antirabbit-Ig-fluorescein isothiocyanate (Kallestad) as the second layer. This procedure was the same as that used in the indirect immunoperoxidase technique, except that no blocking of endogenous peroxidase was necessary.

The heterologous antisera were rabbit antisera to human class II $(\mathrm{p} 28,33)$ antigens and human T lymphocyte antigen (HuTLA), and purified antibodies to goat antihuman $\mu$ heavy chain. ${ }^{7}$ A monoclonal antibody, $\mathrm{J} 5$, to common ALL antigen ${ }^{8}$ was also used. The second layer was goat antimouse Ig-TRITC (made locally).

\section{Results}

BIOPSY RESULTS WITH NO TdT POSITIVE CELlS Table 1 shows the result of clinical, histological, and immunological findings. In group 130 patients had a negative biopsy with no TdT positive cells, and eight of these patients have subsequently relapsed. Two of these had testicular relapse at eight and 35 months, respectively. On repeat biopsy the testis in the first

Table 1 Correlation of histological observation with presence of TdT positive cells in testis of patients with ALL

\begin{tabular}{|c|c|c|c|c|c|}
\hline \multirow[b]{2}{*}{ Group } & \multirow[b]{2}{*}{ No of patients } & \multicolumn{2}{|l|}{ Assessment } & \multirow{2}{*}{$\begin{array}{l}\text { TdT positive cells } \\
\text { in sections }\end{array}$} & \multirow[b]{2}{*}{ Outcome } \\
\hline & & Clinical & Histological & & \\
\hline 1 & 30 & Normal & Normal & Negative* & $\begin{array}{l}22 \text { well } 8 \text { relapsed } \\
\text { ( } 2 \text { testis, } 3 \text { bone marrow, } 1 \text { central } \\
\text { nervous system, } 2 \text { combined central } \\
\text { nervous system }+ \text { bone marrow) }\end{array}$ \\
\hline 2 & 2 & Normal & Infiltrated & Negative & $\begin{array}{l}\text { Both well } \\
\text { (one received further treatment) }\end{array}$ \\
\hline $\begin{array}{l}3 \\
4\end{array}$ & $\frac{3(+1)}{2}$ & $\begin{array}{l}\text { Infiltrated } \\
\text { Normal }\end{array}$ & $\begin{array}{l}\text { Infiltrated } \\
\text { Normal }\end{array}$ & $\begin{array}{l}\text { Positive } † \\
\text { Rare positive } \ddagger\end{array}$ & $\begin{array}{l}\text { All treated; } 2 \text { well } \\
\text { Both well }\end{array}$ \\
\hline
\end{tabular}

*No TdT positive cells detectable in the whole section; +Cases $2-4$ in table 2 ; $¥ T d T$ positive positivity on four and six cells in the section with negative controls.

Table 2 Phenotypic features of lymphoid infiltrates in testis of patients treated for ALL*

Positivity with antisera and monoclonal antibodies to antigents:

\begin{tabular}{llllll}
\cline { 2 - 6 } Case No & TdT & $\begin{array}{l}\text { HuTLA } \\
\text { (T cell associated })\end{array}$ & Class II & IgM & $\begin{array}{l}\text { J5 anti-ALL } \\
\text { monocl. Ab }\end{array}$ \\
\hline 1 & $<1$ & $30^{*}$ & 70 & NT & NT \\
2 & $>90$ & NT & $>95$ & 70 & $>95$ \\
3 & $>90$ & $<5$ & $>95$ & $<5$ & $>95$ \\
4 & $>90$ & $>5$ & $>95$
\end{tabular}

*Numbers refer to the percentages of cells within the infiltrating lymphoid population, + the results show that this is a pre-B ALL. 


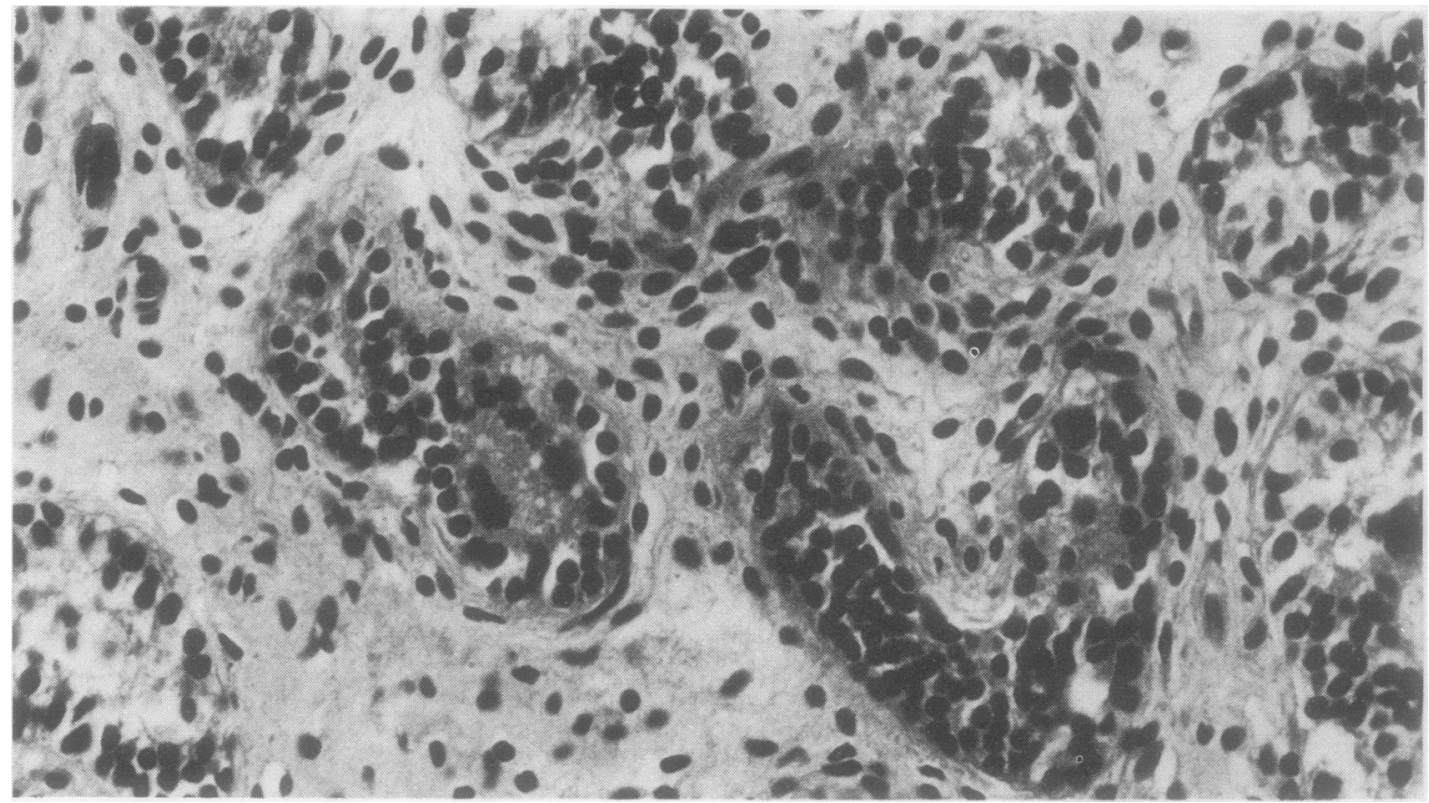

Fig 1 Testicular biopsy specimen showing immature seminiferous tubules appropriate to age of patient. Oedematous interstitial tissue contains infiltrate of lymphocytes, but no leukaemic cells are seen. (Haematoxylin and eoxin.) $\times 315$.

case was heavily infiltrated with TdT positive cells (case 2 in table 2); immunological studies were not performed on the second case. Three patients in group 1 relapsed in the bone marrow, one in the central nervous system, and two in both central nervous sys- $\odot \vec{\oplus}$ tem and marrow. Twenty two patients in group 10 remained in remission and off treatment at 35 to 65 months with a median follow up of 48 months. Five $\sqsupseteq$

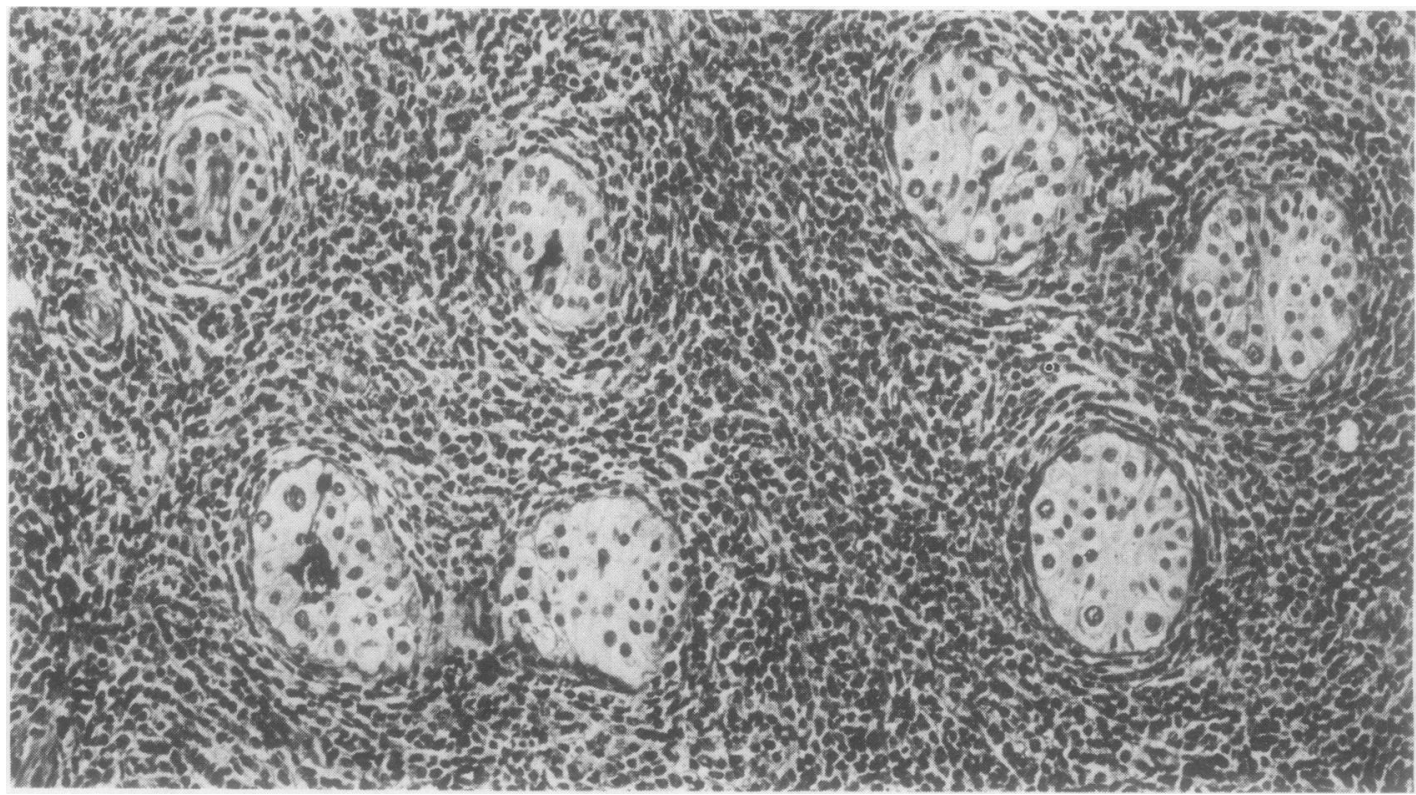

Fig 2 Immature seminiferous tubules are widely separated by heavy leukaemic infiltrate in interstitial tissue.

(Haematoxylin and eosin.) $\times 125$. 
of these 22 patients had a biopsy specimen apparently infiltrated with mature lymphocytes (fig 1 ). In four the histological appearances had been thought to be unquestionably benign, and immunological analysis subsequently confirmed that no TdT positive cells were present. In the fifth (case 1, table 2) the results of immunological analysis were made available at the time of biopsy (the only case in the series) and confirmed the benign nature of the infiltrate. All five of these patients in group 1 remained well and off treatment.

In group 2 two children had biopsy specimens which were considered to have shown infiltrates on histological review but were subsequently shown to be TdT negative. One boy was treated for relapse for two years and subsequently remained well off all treatment at 25 months. The second had originally been thought to have had a normal biopsy specimen, but it was considered to be infiltrated on review; no treatment was given and he remained well at 36 months.

\section{BIOPSY RESULTS WITH TdT POSITIVE CELLS}

In three patients with overt testicular leukaemia plus one additional child with a previously negative biopsy specimen the histological appearances were those of leukaemic infiltration (fig 2) and immunohistological analysis showed $>90 \%$ TdT positive cells (group 3 ). The membrane marker analysis available in three of the four biopsy specimens showed that these cells had features of common ALL in two cases (cases 3 and 4 in table 2; positive for HLA class II and for common ALL antigen, respectively). One boy (case 2) also reacted with antibodies to TdT, class II, and common ALL antigen and in addition showed cytoplasmic IgM (pre-B ALL).

These patients were treated. One patient seemed slow to respond and underwent orchidectomy. The testis was reinvestigated with both histology and TdT staining. Both studies indicated the absence of leukaemic blasts, showing that the treatment had effectively eliminated heavy infiltrates of cells.

Finally, two patients (group 4) with histologically negative biopsy specimens seemed to have a few TdT positive cells. At that time (before Feburary 1981) no double membrane marker studies had yet been performed to confirm the HLA class II positivity of these blast cells. Both of these patients stopped treatment and remained well at 60 and 62 months from the time of the biopsy.

\section{Discussion}

These studies confirm previous investigations ${ }^{69}$ by showing that the detection of terminal transferase enzyme for the histological diagnosis of leukaemic and lymphomatous infiltrates is feasible. A correlation was observed between the histological and immunological diagnosis in 35 of 39 biopsy specimens: $\mathbf{3 0}$ with no clinical evidence of leukaemic infiltration; one repeat biopsy following treatment; and four biopsies with heavy infiltrates. Two of the 30 boys who had a negative biopsy specimen before stopping treatment subsequently had an isolated testicular relapse in spite of the fact that the testicular biopsy specimen had no identifiable malignant cells during histological and immunological investigations. It seems, therefore, that TdT staining will not improve the early diagnosis of isolated testicular relapse, which had a failure rate of $7 \%$ in a previous study. ${ }^{2}$ It has been suggested that occult foci of testicular leukaemia may reseed the bone marrow and cause late marrow relapse after treatment has been stopped. ${ }^{10}$ In this study no evidence was found to support this theory: no TdT positive cells were found in the biopsy specimens from five boys who subsequently had a bone marrow relapse.

One difficulty was the identification of a few isolated apparently TdT positive cells in two samples from boys who subsequently did not develop isolated testicular relapse. Isolated mast cells and granulocytes can show misleading positive staining even with absorbed reagents. The importance of these cells critically depends on the careful reading of the same areas in the control samples, but single mast cells may be missed. Safer diagnosis can be made by double labelling using TdT, together with class II or common ALL antigen, as has recently been shown in tissue biopsy specimens. $^{11}$

Finally, this study highlights the problems of interpreting lymphocytic infiltrates in testicular biopsy samples. One child who was deemed on review to have had leukaemic infiltration remained well without specific treatment and the diagnosis was not supported by the finding of TdT positive cells. The benign nature of the infiltrate in case 1 was confirmed by immunohistology. Thus immunohistological methods are useful in confirming the benign inflammatory nature of lymphocytic testicular infiltrations. ${ }^{12}$

In conclusion, these observations indicate that in difficult cases with suspicious infiltrates an immunohistological study combined with rabbit anti-TdT and monoclonal antibodies to membrane antigens might be helpful. The routine screening of testicular biopsy specimens with single antibodies has, however, no additional use in conventional histology.

This study was supported by the Leukaemia Research Fund of Great Britain. Dr JA Thomas and Professor G Janossy participated in the study.

\section{References}

1 Tiedemann K, Chessells JM, Sandland RM. Isolated testicular relapse in boys with acute lymphoblastic leukaemia: treatment and outcome. $\mathrm{Br}$ Med J 1982;285:1614-6. 
2 Eden OB, Rankin A, Kay HEM. Isolated testicular relapse in acute lymphoblastic leukaemia of childhood. Arch Dis Child 1983;58:128-31.

3 McCaffrey RP, Harrison A, Parkman BS, Baltimore D. Terminal deoxynucleotidyl transferase activity in human leukaemic cells and normal thymocytes. $N$ Engl J Med 1975;292:775-80.

4 Bollum FJ. Terminal deoxynucleotidyl transferase as a hematopoietic cell marker. Blood 1979;54:1203-15.

5 Janossy G, Bollum FJ, Bradstock KF, Ashley J. Cellular phenotypes of normal and leukaemic haemopoietic cells determined by analysis with selected antibody combinations. Blood 1980;56:430-41.

6 Thomas JA, Janossy G, Eden OB, Bollum FJ. Demonstration of nuclear terminal transferase deoxynucleotidyl transferase (TdT) in leukemic infiltrates of testicular tissue. $\mathrm{Br} J$ Cancer 1982;45:709-17.

7 Janossy G, Bollum FJ, Bradstock KF, McMichael A, Rapson N, Greaves MF. Terminal transferase positive human bone marrow cells exhibit the antigenic phenotype of common acute lymphoblastic leukemia. J Immunol 1979;123:1525-9.
8 Ritz J, Pesando JM, Notis-McConarty J, Lazarus H, Schlossman SF. A monoclonal antibody to human acute lymphoblastic leukaemia antigen. Nature 1980;283:583-5.

9 Halverston CA, Falini B, Taylor CR, Parker JW. Detection of TdT in paraffin sections with the immunoperoxidase technique. Am J Pathol 1981;105:241-54.

10 Chessells JM. [Commentary]. Arch Dis Child 1983;58:131-2.

11 Chilosi M, Pizzolo G, Fiore-Donati L, Bofill M, Janossy G. Routine immunofluorescent and histochemical analysis of bone marrow involvement of lymphoma/leukaemia - the use of cryostat sections. Br J Cancer 1983;48:763-75.

12 Janossy G, Thomas JA. Immunohistological diagnosis of lymphoproliferative diseases by selected combinations of antisera and monoclonal antibodies. Br J Cancer 1980;42:224-42.

Requests for reprints to: Dr JM Chessells, Department of Haematology, The Hospital for Sick Children, Great Ormond Street, London WC1N3JH, England. 